\title{
Gastric Cancer: Molecular Pathology State
}

\author{
Filomena Altieri, Paolo Arcari and Emilia Rippa \\ Additional information is available at the end of the chapter \\ http://dx.doi.org/10.5772/53757
}

\section{Introduction}

Despite the progressive decrease observed in the past fifty years, gastric cancer (GC) is the fourth of the world rankings incidence of various types of cancer and is the second as a cause of cancer-related death. There is distinct geographical variation in gastric cancer incidence with the highest rates reported from Japan, Korea and Eastern Asia. Other high incidence areas are Eastern Europe and parts of Latin America, while Western Europe, Africa, Australia and the US generally have low incidence rates. In the last decade there has been a downward trend in the incidence and mortality from this cancer. The reasons are to be found in the improvement of food both as regards its preservation procedures and the variability in the diet and for the decrease of infection by Helicobacter pylori (H. pylori). H. pylori infection is strongly associated with risk for stomach cancer. Likely, this association is supported by the strong link between this bacterium infections and precancerous lesions, including chronic atrophic gastritis and dysplasia. The development of gastric cancer is characterized by multistage process in which several alterations of genetic and epigenetic nature accumulate. These alterations are mainly related to abnormalities of growth factors and receptors, DNA mismatch repair genes, angiogenic factors, transcription factors, adaptor proteins, cell cycle regulators, and many other macromolecular cell components. All these abnormalities identify from one side the molecular and biological aspect of gastric cancer cells and from the other might suggest possible strategies for therapeutic intervention.

The most important epigenetic alterations are confined within the chromatin structure like chromatin remodeling, DNA methylation and histone modification. These molecular alterations are generally common in gastric cancer, independently from its classification (gastric or intestinal). Also genetic polymorphism represents a possible endogenous cause of cancer risk. However, it must be considered that genetic polymorphisms might influence the efficacy of gastric cancer therapy and the toxicity of anticancer drugs. Although the worldwide decline in incidence and recent diagnostic and therapeutic advances provided excellent survival for 
patients with early gastric cancer, the prognosis of patients with advances cancer is still poor. Over the past 15 years, integrated research, including genetic polymorphism and global analysis of gene expression has clarified detailed molecular mechanisms and the role of genetic and epigenetic abnormalities of cancer-related genes in the course of development and progression of gastric cancer. This review describes an outline of the molecular pathway of stomach carcinogenesis, as signaling pathways, H. pylori, epigenetic and oncogenic background of gastric cancer, and recent treatment modalities.

\section{Risk factors and classification}

The general decrease of gastric cancer frequency in developed countries is attributed to the changes in dietary habits and food preservation methods [1]. Chronic inflammation with gastric atrophy was shown to be the most important pathological entity with hypochlorhydria being the most important physiological abnormality. Alcohol and smoking are also thought to contribute to the etiology. Achlorhydria, pernicious anaemia and blood group A are also associated with a higher risk of gastric malignancy. However, following the discovery of $\mathrm{H}$. pylori it is known that more than $80 \%$ of gastric cancer cases can be attributed to deregulation of signaling pathways caused by H. pylori infection [2]. Genetic syndromes are rare and families clustering of gastric cancer are usually attributed to common H. pylori infection. A family syndrome of gastric cancer due to germ-line mutation in E-cadherin has been described, and gastric cancer may be part of Lynch syndrome (HNPCC). Mutations and polymorphism of interleukin $1 \beta$ (IL-1 $\beta$ ) and Tumor Necrosis Factor $\alpha(\mathrm{TNF} \alpha)$ have been described in closer relatives of patients affected by gastric cancer, and considered predictive factors for cancer. Genetic polymorphism is an important endogenous cause and modulator of risk for developing gastric cancer. They include: 1) inflammatory responses to $H$. pylori infection such as variants of IL-1 $\beta$ and IL-1 receptor antagonist (IL-RA); 2 ) intrinsic variability of DNA repair processes; 3) function of carcinogen detoxification and antioxidant protection; 4) cell proliferation activity [3].

GC is characterized by two distinct histological type of adenocarcinoma (intestinal type and a diffuse type) each having different epidemiological and pathophysiological features [4]. The intestinal-type generally evolves through a relatively well-defined multistep process that starts from chronic gastritis and progresses to chronic atrophy, intestinal metaplasia and dysplasia $[5,6]$. It is associated with H. pylori infections and certain dietary factors, such as high intake of salt, smoked meats and food preserved with nitrites or nitrates [7, 8]. Intestinal tumors consist of malignant cells that resemble functional glands of the gastrointestinal tract. They are well differentiated and occur more commonly in older patients, males and blacks. The diffusetype has instead a poorer prognosis and develops from normal gastric epithelium through unknown genetic and morphological events. It comprises cells that lack cohesion and are no longer capable of gastric function and it is more frequent in younger patients [9]. Several common events are shared between the two histological GC subtypes whereas distinct differences also highlight the intriguing divergence in histogenesis. The etiology of these differences remains to be elucidated $[10,11]$. 


\section{H. pylori infection}

The pathogenesis of gastric cancer remains poorly understood although it is evident that several environmental factors, such as H. pylori infection can be the cause leading to this disease.

H. pylori infection is associated with risk for both the intestinal and diffuse varieties of gastric cancer. In fact, the risk to develop gastric cancer is increased in patients with H. pylori infections probably as the result of a combination of genetic and environmental factors in which the infection by $\mathrm{H}$. pylori is of particular relevance, especially when the inflammation involves the gastric body region with respect to the antrum $[6,12,13]$. Generally, this condition is associated to different degrees of atrophy and alterations of the secretory function that, in the long term, became associated to gastric carcinoma [14-16]. The positive correlation between H. pylori infection and development of gastric cancer is well established and proven in prospective controlled studies $[17,18]$, whereas in absence of infection, development of gastric carcinoma constitutes a rare event. Furthermore eradication of $\mathrm{H}$. pylori leads to a substantial reduction the risk of gastric cancer. From a pathogenetic point of view, it is believed that $\mathrm{H}$. pylori infection determines the release of free radicals, resulting in mitogen stimulation and the inflammatory response of the stomach epithelium. The pathogenesis is associated with two bacterial genes known as CagA (Cytotoxic Associated Gene-A) and VacA (Vacuolating cytotoxin gene-A). The CagA gene is a marker for about twenty genes capable of increase the turnover of gastric epithelium through the CagA protein release. As a result, the association with an increased risk of developing non-cardia gastric cancer seems to be associated to H. pylori strain CagA [19]. A key role seems to have the so-called nuclear factor kB (NF-kB) [20]. NF-kB activation is in fact not only limited to patients with H. pylori active infection,but its nuclear and cytoplasmic expression appears to be up-regulate in gastric adenocarcinoma compared to adjacent normal tissue. The key role that this protein plays is also confirmed by the correlation between its expression and tumor conditions: biological and clinical aggressiveness, lymphatic invasion, tumor size and metastasis [21].

Among the targets of CagA strain there is also RUNX3, a tumor suppressor in many tissues and frequently inactivated in gastric cancer. Recently, it has been shown that $\mathrm{H}$. pylori infection inactivates RUNX3 in CagA-dependent manner: CagA directly associates with RUNX3 through the specific recognition between the PY motif of RUNX3 and the WW domain of CagA [22].

\section{Molecular pathology}

The bacterial, environmental and host genetic factors discussed above influence the development of gastric carcinoma. Genomic, proteomic and biotechnology could allow the identification of novel genes and molecules specifically up-regulated or down-regulated in gastric cancer. Advances in our understanding of the genetic and molecular bases of gastric cancer lead to improved diagnosis, personalized medicine and prevention of gastric cancer. 
In the following section, we discuss some of the molecular mechanisms underlying the molecular pathway of stomach carcinogenesis and of the biological and clinical roles of recently identified genes involved in gastric cancer.

\subsection{GKN1}

Recently, a novel tissue-specific protein, gastrokine1 (GKN1), has been isolated from gastric mucosa cells of several mammalian species, including mouse [23]. The human GKN1 gene has been localized in a $6 \mathrm{~kb}$ region of the chromosome $2 \mathrm{p} 13$ and contains 6 exons [24]. GKN1 is found within the granules just under the apical plasma membrane, suggesting that it is a secreted rather than a membrane protein. GKN1 has been hypothesized to play an important role in maintaining the integrity of the gastric mucosa and mediating repair after injury. Oien et al. [25] demonstrated, by Northern blotting, that GKN1 mRNA was abundant only in normal human stomach, in all areas (cardia, body and antrum), but absent in gastric adenocarcinomas; gastro-oesophageal adenocarcinoma cell line and other normal and tumor gastro-intestinal tissues. Therefore, there is a transcriptional silencing of GKN1 gene in gastric cancer. Rippa et al. [26] recently demonstrated, by means of proteomic technology, that GKN1 protein is reduced in patients with $H$. pylori-positive chronic gastritis. In addition, from the analysis of 28 patients with gastric cancer, Nardone et al. [27, 28], showed the downregulation or the complete absence of the protein. Similarly, Shiozaki et al. [29] showed that transfection with GKN1 reduced colony formation in MKN-28 gastric carcinoma cells. These data suggest that GKN1 participates in the host response to $H$. pylori and may also function as gastric tumorsuppressor gene [30]. More recently, new interesting data about GKN1 are emerging. Jung Hwan Yoon et al. [31] observed in GKN1-transfected AGS cells the inhibition of the epithelialmesenchymal transition (EMT), a biological process that allows a polarized epithelial cell to undergo multiple biochemical changes that enable it to assume a mesenchymal cell phenotype, including enhanced migratory capacity, invasiveness, and elevated resistance to apoptosis. Also, GKN1-transfected and recombinant GKN1-treated AGS cells showed decreased levels of reactive oxygen species (ROS) and of phosphatidylinositol 3-kinase (PI3K)/Akt pathway proteins, which are a major cascade mediating tumor metastasis, accompained by re-expression of E-cadherin (a cell adhesion molecule which prevents EMT) and decreased expression of cytoplasmic and nuclear b-catenin, slug, snail, fibronectin, and vimentin (EMT-related proteins). These data suggest that the GKN1 gene may play an important role in the progression of sporadic gastric cancers via inhibition of EMT and cancer cell migration. Xing et al. [32] showed instead that GKN1 is an autocrine/paracrine protein that inhibits cell growth due to senescence resulting from activation of $\mathrm{p} 16 / \mathrm{Rb}$ and $\mathrm{p} 21$ waf pathways. Furthermore, sustained activation of Ras/Raf/MEK/ERK signalling was characterised in gastric cancer cells and xenograft nude mouse model following GKN1 treatment. Therefore, this study provides molecular evidence that GKN1 induces also senescence of gastric cancer cells.

Our group has been studying the effect of GKN1 on gastric cancer cell lines (AGS and MKN28). We found by cytofluorimetry, Western blot and RT-PCR that overexpression of GKN1 in these cell lines stimulated the expression of Fas receptor. Moreover, compared to control cells, a significant increase of apoptosis, evaluated by TUNEL, was observed when GKN1 transfected 
cells were treated with a monoclonal antibody $(\operatorname{IgM})$ anti-Fas. The activation of Fas expression was also observed by the overexpression of GKN1 in other cancer cell lines. GKN1-overexpressing gastric cancer cells exposed to FasL induced the activation of caspase- 3 was as evaluated by Western blot and fluorescence assays [33]. In addition, MTT assay showed that recombinant GKN1 reduced cell proliferation of gastric cancer cells (AGS) compared to human embryonic kidney cell line (HEK 293) and non-gastric cancer cells, human lung epidermoid carcinoma cell line (H1355). Our data represent the first report for GKN1 as modulator of apoptotic signals and suggest that GKN1 might play an important role for tissue repair during the early stages of neoplastic transformation. In fact, it was seen that individuals with a lower expression of the protein have an increased risk to develop gastric diseases [34].

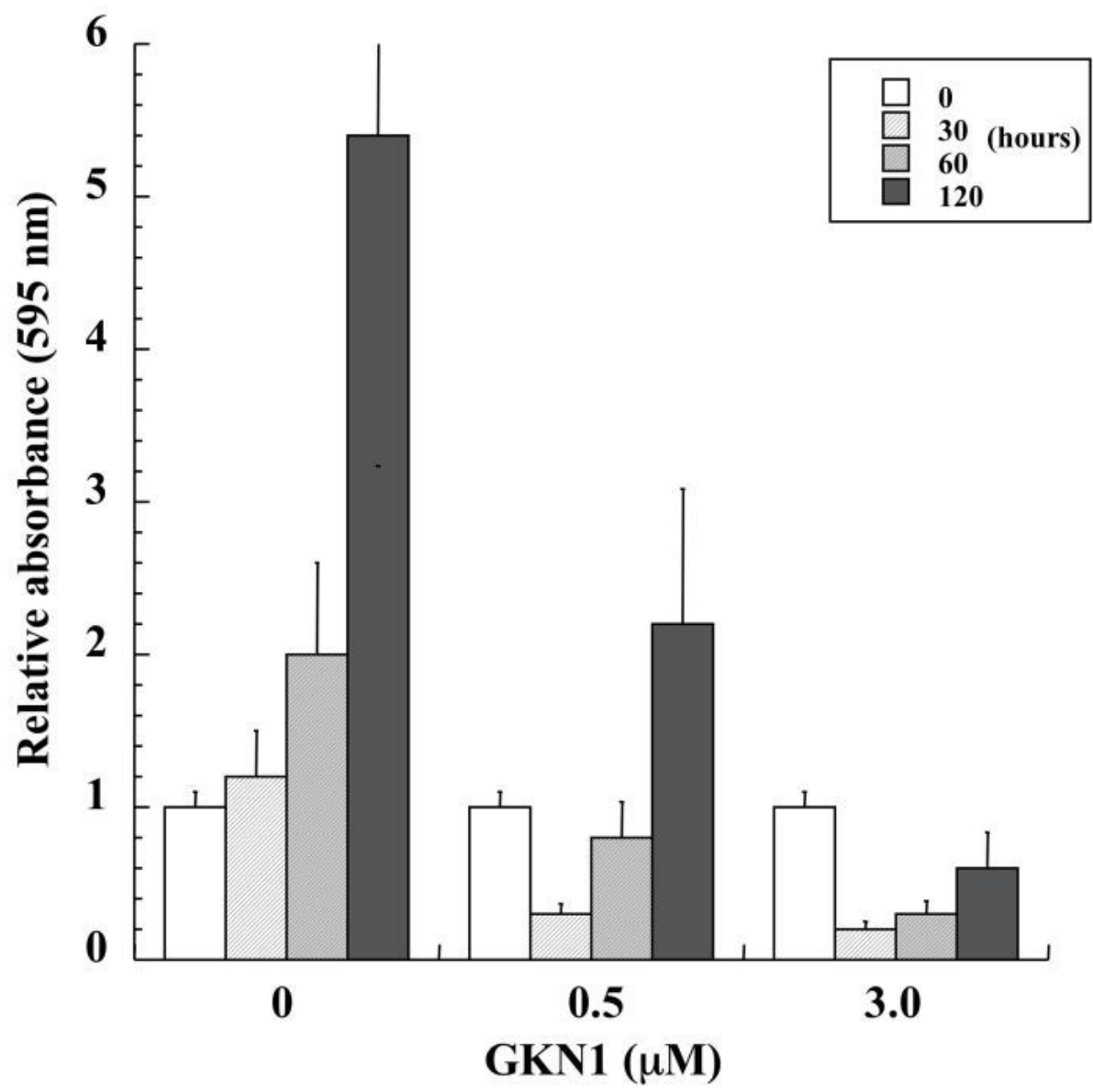

Figure 1. Effects of GKN1 on cell growth. AGS cell growth was evaluated using the MTT procedure after incubation of the cells with recombinant GKN1 at different times and concentrations. The data reported represent the average of three independent experiments. 
Finally, regarding the mechanism by which GKN1 gene is silenced in gastric cancer, this remains still unknown however, Hwan Yoon et al. [35] investigated this aspect in a sample group of 81 gastric carcinomas and 40 gastric adenomas: no mutation was detected in gastric tumours, hyper-methylation of GKN1 gene promoter was found only in two tumours and DNA copy number of GKN1 was significantly decreased in gastric cancer. However, epigenetic mechanisms could also contribute to silencing GKN1 gene. Under this aspect, it would be important to clarify the causes of GKN1 gene silencing and to determine whether this event might be involved in the development and progression of gastric cancer. Additional functional and translational studies of GKN1 will broaden our understanding of the pathogenesis of gastric cancer, and provide us with novel diagnostic and therapeutic modalities in gastric cancer.

\subsection{E-cadherin and the Wnt system}

The signal transduction pathway called Wnt is a central mechanism for regulating gene expression and is highly conserved in vertebrates and invertebrates. It includes a large family of ligands and plays a key role in many cellular processes, which ranging from regulation of embryogenesis control processes the proliferation of mature cells. In particular, it seems crucially involved in the processes of differentiation and proliferation of stem cell elements [36]. Central to these mechanisms is the process of regulation of expression of the $\beta$-catenin, an intracellular protein able to communicate on the surface of the cell with the system of cadherine, but also to act as nuclear transcription factor, including the Wnt/Wingless, epidermal growth factor (EGF), hepatocyte growth factor (HGF), and insulin-like growth factor (IGF) signaling pathways [37-40].

The Wnt signalling pathway can be activated trough the binding of Wnt ligands to their receptors Frizzled (Fz) and low-density lipoprotein receptor-related protein LRP5 and LRP6 (Figure 2). The binding induces an activation signal direct protein Dishevelled (DSH) and axin, that once activated, inhibit GSK3 kinase. Normally GSK3 phosphorylates $\beta$-catenin as part of a multiprotein complex that includes GSK3, APC and axin. The phosphorylation triggers the degradation of $\beta$-catenin through the process of ubiquitination (Figure 2, left panel). It follows that the inhibition Wnt-induced GSK3 interferes with the process of degradation of $\beta$-catenin and causes its cytoplasmic accumulation in a non-complexed form [41]. As consequence, $\beta$ catenin goes into the nucleus and regulates target gene transcription through association with the transcription factor TCF/ LEF (lymphoid enhancer binding factor) (Figure 2, right panel).

The translocation into the nucleus of $\beta$-catenin eventually leads to transcription of several genes including protagonists of carcinogenesis known protooncogenes such as c-myc and cyclin D1. In this regard, it is interesting that GSK3 can be inhibited through the PI3K/AKT pathway after toxin VacA stimulation [42]. This is a further element to support the correlation between infection by H. pylori and gastric carcinogenesis. Cell adhesion molecules may act as tumour suppressors such as E-cadherin whose gene is mutated in about $50 \%$ of diffuse type gastric carcinoma [43]. This homophilic cell adhesion molecule belongs to a family of cell-cell adhesion molecules with an important role in intercellular adhesion by establishing cell polarity, maintaining tissue morphology and cellular differentiation in normal cells [44, 45]. 

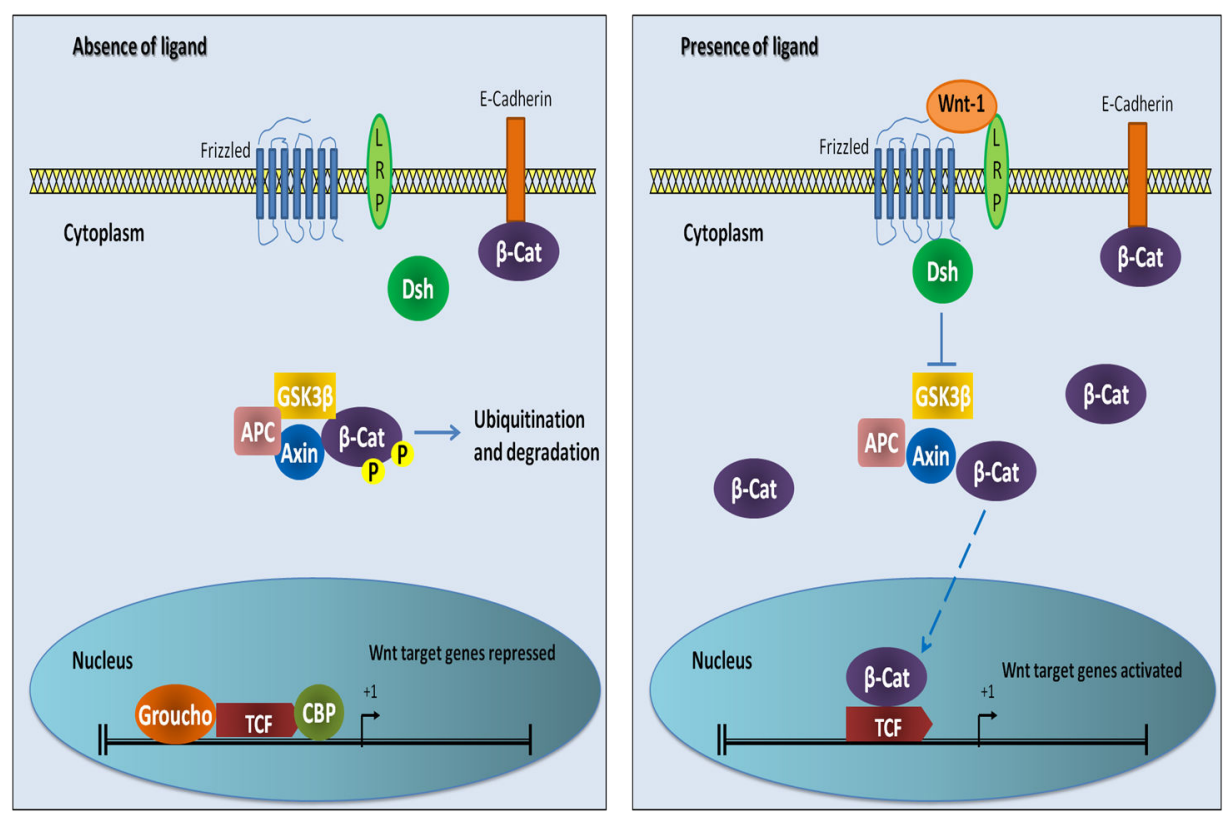

Figure 2. The Wnt signaling pathway. In the absence of Wnt ligand (left panel), the destruction complex (GSK3 $\beta, A P C$, Axin) creates a hyperphosphorylated $\beta$-catenin, which is a target for ubiqitination and degradation by the proteosome. Binding of Wnt ligand to a Frizzled/LRP-5/6 receptor complex (right panel) leads to stabilization of hypophosphorylated $\beta$-catenin, which interacts with TCF/LEF proteins in the nucleus to activate transcription. $\beta$-catenin normally binds to the intracellular domain of E-cadherin but the whole Wnt pathway is independent of E-cadherin expression.

E-cadherin binds to the actin cytoskeleton via a series of catenin proteins [46]. Therefore changes in E-cadherin expression have a direct effect on cell adhesion and therefore plays an important step in cancer development. Mutations in $\beta$-catenin and $\gamma$-catenin have also been observed in gastric cancer cell lines, and together with E-cadherin mutations appear to be involved in the development and progression of diffuse and schirrhous type cancers [47-49]. As the E-cadherin is responsible for the seizure of a major fraction of $\beta$-catenin in the compartment intracellular membrane, a loss of E-cadherin complexed to the cell membrane is associated with an increase in the share intracytoplasmic and nuclear of $\beta$-catenin [50]. In fact, this possibility is confirmed by immunophenotypic analysis of tumor diffuse gastric, where it often shows the increasing of nuclear $\beta$-catenin expression is associated with reduced of immunolocalization of membrane of the E-cadherin [51]. Recent data indicate that the simple down-regulation of E-cadherin, also obtained through epigenetic mechanism, alone would be sufficient to trigger the molecular carcinogenesis diffuse type of gastric cancer [52]. Despite the alterations of the E-cadherin seem limited to diffuse forms, also in carcinoma of intestinal type are observed alterations of the Wnt pathway that leads to an increase of cytosolic and nuclear $\beta$-catenin [53]. This accumulation of $\beta$-catenin can be explained by mutations in APC gene (Adenomatous Polyposis Coli) or in $\beta$-catenin gene itself. Both the situations lead to a 
hypophosphorylation of $\beta$-catenin, which reduces its proteolytic degradation. This is again an accumulation of intracytoplasmic $\beta$-catenin resulting in its nuclear translocation, where it can exert oncogenic role. A mutation of the APC gene appears be found in approximately $30 \%$ of adenocarcinomas of type intestinal [54]. To further support the role of Wnt, has observed that patients with germline mutations of APC present a risk of developing gastric cancer 10 times higher than that of the normal population [55].

\subsection{RUNX3}

Another potential candidate in the molecular carcinogenesis process of stomach cancers is represented by RUNX3, one of the first identified members of the RUNX family (mammalian Runt related genes) [56]. The RUNX gene family is composed of three members, RUNX1/ AML1, RUNX2 and RUNX3 [57]. These are genes coding for a group of closely related proteins with DNA binding function. In humans, loss of RUNX3 by hypermethylation of the promoter CpG islands is observed in several different cancers, including $64 \%$ of gastric carcinomas [58]. This loss reaches $90 \%$ in patients with gastric cancer in advanced stage. Gastric epithelium of RUNX3 knockout mice exhibits hyperplasia, reduced rate of apoptosis and reduced sensitivity to TGF $\beta 1$, thus suggesting that the tumour suppressor activity of RUNX3 operates downstream of the TGF $\beta$ signaling pathways. RUNX3 methylation is also a feature of $8 \%$ of chronic gastritis, $28 \%$ of intestinal metaplasia and $27 \%$ of gastric adenomas. These observations suggest RUNX3 is a target for epigenetic gene silencing in gastric carcinogenesis [59, 60]. Another element of great interest that correlates RUNX3 to H. pylori infection is represented by the fact that the H. pylori infection may down-regulate RUNX3 with an epigenetic mechanism [61]. In fact, it has been observed that during $\mathrm{H}$. pylori infection there is the induction of nitric oxide production by macrophages resulting in methylation of the RUNX3 promoter. Recent results also show how the loss of expression of RUNX3 correlatessignificantly with the metastatic spread of cancer by adversely affecting the prognosis [62].

\subsection{Genomic instability}

In gastric cancer the loss of genomic stability represents a key molecular step that occurs early in the carcinogenesis process and creates a permissive environment for the accumulation of genetic and epigenetic alterations in tumor suppressor genes and oncogenes. It iswidely accepted that gastric cancer can follow at least two major genomic instability pathways, chromosome instability (CIN) and microsatellite instability (MSI). CIN is defined as the loss of chromosomal material during dysfunctional chromosome replication, repair or segregation [63]. MSI, which results from an erroneous DNA mismatch repair system, has been well known to be involved in the carcinogenesis of hereditary nonpolyposis colon cancers and some of sporadic colorectal cancers $[64,65]$. A variable fraction from $15 \%$ to $50 \%$ of sporadic gastric cancer ischaracterized by MSI as a result of genetic inactivation or mainly Mismatch Repair (MMR) genes epigenetics, including hMLH1 and hMSH2. The inactivation of MMR genes is not itself a transforming event and additional genetic changes are required for progression to malignancy. In particular, in gastric cancer MSI is observed with the presence of mutations in repetitive sequences of genes involved in the regulation of cell growth (TGF- $\beta$ RII, IGF-IIR), in 
apoptosis (BAX) and DNA repair (hMSH6, hMSH3). These mutations can alter the gene expression and give an advantage in cell growth and in clonal expansion. GC with MSI represents a tumor subset with clinico-pathological specific features. In particular, MSI GC is an intestinal gastric cancer, with antral location, low prevalence of vascular invasion or lymph node infiltration and better prognosis.

\section{The molecular aspect of gastric cancer as rational for new therapeutic targeted strategies}

In recent years it has strengthened the tendency to identify therapeutic strategies different from classical chemotherapeutic approach. The reviewed signaling pathways are relevant contributors for gastric carcinogenesis and encompass a multitude of potential therapeutic targets. In particular, there are growing efforts designed to identify the molecular mechanisms whose inhibition can significantly reduce the clinical aggressiveness of tumor malignacy. This innovative approach has achieved major successes in rare neoplastic diseases such as chronic myeloid leukemia and gastrointestinal stromal tumors (GIST) where it was possible to effectively inhibit constitutionally activated receptor tyrosine kinase such as the KIT gene [66, 67]. Except for the inhibition of HER 2 in breast carcinoma, the same success has not yet been achieved in other tumors hence the need to further investigate on the existence of new potential molecular targets. Under this aspect, GC is not an exception indeed it represents a disease for the possible application of targeted therapies.

\subsection{HER 2}

HER2 (Human Epidermal Growth Factor Receptor 2) also known as Neu, ErbB-2, CD340 (cluster of differentiation 340) or p185 is part of a large family of receptors of tyrosine kinase activities. Along with HER1, also known as EGFR, up-regulation of HER2 is an important event in molecular carcinogenesis of many cancers. Ligand binding to EGFR extracellular domain leads to its activation, with subsequent homodimerization leading to the phosphorylation of its intracellular tyrosine kinase domain. This will initiate a series of intracellular signals, including activation of the central Ras/Raf/mitogen activated protein kinases (MAPK) signaling pathway (Figure 3). Up to now, the best model known is constituted by breast carcinoma in which HER2 is amplified in about $20 \%$ of cases [68]. This amplification is correlated to an increase of the expression of the protein and thus in growth advantage [69]. The prognostic negative role played by the amplification of HER 2 in breast cancer is balanced by the possibility to interfere with that oncogenetic mechanism through the use of molecular therapies targeted with humanized monoclonal antibodies (i.e. Trastuzumab) [70]. On the basis of the results obtained in the treatment of breast cancer and counting on the fact that gastric carcinomas show amplification of HER 2 in approximately $20 \%$ of cases, clinical trials have been designed that demonstrated significant improvement in progression-free survival disease for patients with HER2 overexpression, treated with trastuzumab, particularly when associated to conventional chemotherapy [71-73]. It is interesting to note how the aberrations of HER2 are 
practically exclusive of gastric (and cardial) adenocarcinomas of intestinal type, while they are decidedly not represented in the forms of the diffuse type. As in the case of E-cadherin alterations, there is a correlation between morphological and molecular mechanism in the diffuse forms. The EGFR/MAPK pathway has also shown to be activated in gastric carcinomas with microsatellite instability [74].

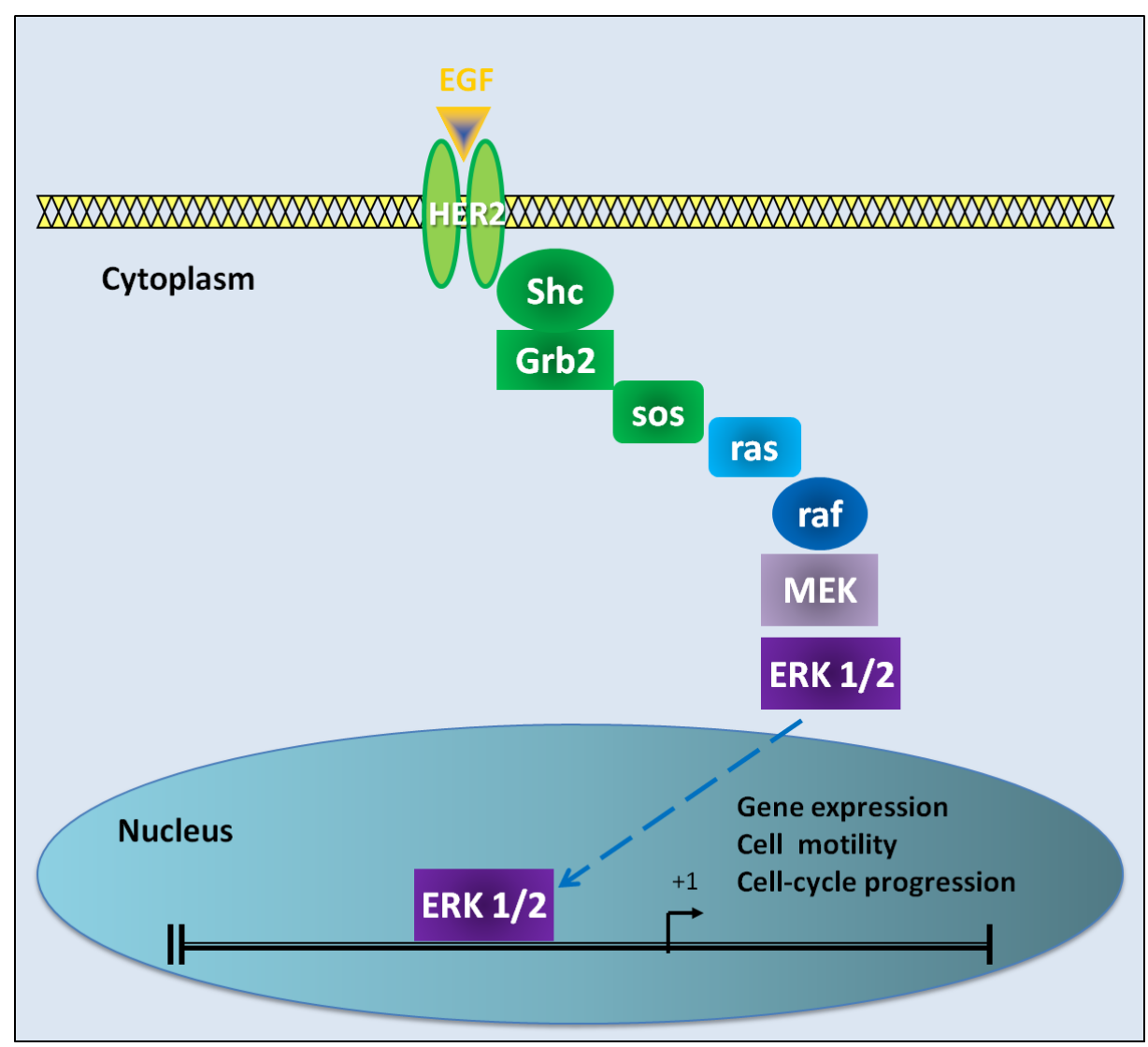

Figure 3. HER2 signaling pathway. Binding of EGF to HER2 initiate a series of intracellular signals, including activation of the central Ras/Raf/mitogen activated protein kinase (MAPK) signaling pathway. 


\subsection{VEGF}

The mechanisms of angiogenesis have recently received a lot of interest in oncology and the inhibition of tumor angiogenesis has become a therapeutic option even feasible in gastric cancer [75]. The vascular endothelial growth factor (VEGF) is a dimeric heparin-binding glycoprotein and it is characterized by the ability to exert a powerful mitogenic action on endothelial cells, promoting their growth both in the primary tumor and in metastases, in the latter case after having stimulated the migration from home neoplastic primitive and secondary levels. A very recent study has shown a direct relationship between VEGF concentrations and new blood vessel development; gastric mucosal neovascularization was also reported to be significantly higher in the antrum of patients with $\mathrm{H}$. pylori-positive gastritis versus noninfected individuals [76]. Experimental studies using different approaches clearly demonstrate that VEGF promotes tumor growth, angiogenesis, and metastasis formation [77, 78]. Overexpression of VEGF levels has been actually observed in the serum of gastric cancer patients compared with normal control and the increase of the expression seems to be correlated with the tumor stage and mass and is a negative prognostic factor [79]. However, there are limited data regarding the clinical and prognostic significance of serum VEGF (sVEGF) levels in gastric cancer patients. The fact that for some years it was possible to interfere with the neoangiogenesis using a recombinant humanized antibody directed against VEGF (bevacizumab) constitutes an element of great clinical interest. Recent is a publication of data from the first Phase II study conducted on patients with advanced or metastatic gastric cancer treated with a combination of bevacizumab, docetaxel and oxaliplatin. Using primary endpoint of progression-free survival, complete responses were observed in 5\%, partial response in $37 \%$ and stabilization of disease in another $37 \%$ of cases. These data certainly encourage randomized trials to definitively clarify whether the inhibition of angiogenesis can be a very effective way in the treatment of gastric cancer.

\section{$5.3 \mathrm{mTOR}$}

The mammalian target of rapamycin (mTOR) pathway has become a major focus of preclinical and clinical cancer research [80]. mTOR is a central regulatory kinase that increases the production of proteins involved in key cellular processes such as cell growth and proliferation, cell metabolism, and angiogenesis [81-83]. mTOR increases translation of proteins that drive cell growth and cell division, such as cyclin D1, and decreases translation of negative regulators of cell cycle progression [84]. It plays a role in cellular metabolism too by stimulating the surface expression of nutrient transporters [85]. mTOR consists in a double molecular complex (mTORC1 and mTORC2). mTORC1 is regulated by two components of the complex tuberous sclerosis (TSC1 and TSC2), which are controlled by the PI3K/AKT. mTORC2 instead regulates AKT cascade. Recently, because of their function in cell proliferation, these molecular complexes were considered ideal target for the design of drugs in oncology [86].

The efficiency of this approach has obtained a first success in a group of rare tumors known as PEComi [87]. However, significant results seem to be possible in the context of solid tumors. In fact, recent data show that the activation of mTOR in gastric cancer represents a key event 
observed in approximately $50 \%$ of cases [88]. Hence, the first attempts to use mTOR inhibitors to improve the efficiency of systemic therapies $[89,90]$.

\section{Conclusions}

In this review, we have summarized reports on genes, proteins and factors involved in gastric carcinogenesis based on currently available literature. Gastric carcinoma results from a complex interaction between bacterial, environmental, host-genetic and molecular mechanisms. It is evident that gastric cancer is the consequence of a multistep process involving different genetic and epigenetic changes in numerous genes. Host genetic background and environmental factors also play an important role in the pathogenesis of the disease. The majority of genetic alterations contributing to the malignant transformation were observed in growth regulatory genes, and in genes involved in cell cycle progression and arrest. In recent years, the analysis of molecular carcinogenesis gastric epithelial neoplasm has certainly provided information of great importance. It is understood that the molecular mechanisms involved in carcinogenesis of intestinal type are different from those prevailing in the development of diffuse one. The element of greater importance from a clinical point lies in the fact that the elucidation of these mechanisms is the prerequisite for exploring innovative therapeutic approaches. While the conventional forms of treatment seem to have reached the limit of effectiveness, it is possible that use of targeted therapies based on solid preclinical rational can translate into tangible clinical benefit. The reviewed signaling pathways are relevant contributors for gastric carcinogenesis and encompass a multitude of potential therapeutic targets. In addition to these signaling-related targets we included new data on

GKN1 as being involved in gastric cancer susceptibility phenotype.

\section{Acknowledgements}

This work was supported by funds from PON Ricerca e Competitivita' 2007-2013 (PON01_02782).

\section{Author details}

Filomena Altieri ${ }^{1}$, Paolo Arcari ${ }^{1,2}$ and Emilia Rippa ${ }^{1}$

1 Department of Biochemistry and Medical Biotechnologies, University of Naples Federico II, Naples, Italy

2 CEINGE, Advanced Biotechnologies Scarl, Naples, Italy 


\section{References}

[1] Crew, K. D, \& Neugut, A. I. Epidemiology of gastric cancer. World J Gastroenterol (2006). , 12(3), 354-362.

[2] Houghton, J, \& Wang, T. C. Helicobacter pylori and gastric cancer: a new paradigm fo inflammation-associated epithelial cancers. Gastroenterology. (2005). , 128(6), 1567-1578.

[3] Yasui, W, Oue, N, Kitadai, Y, \& Nakayama, H. Recent advances in molecular pathobiology of gastric carcinoma. In: The diversity of gastric carcinoma. Springer-Verlag (2005). , 2005, 51-71.

[4] Lauren, P. The Two Histological Main Types of Gastric Carcinoma: Diffuse and SoCalled Intestinal-Type Carcinoma. An Attempt at a Histo-Clinical Classification. Acta Pathologica et Microbiologica Scandinavica (1965). , 64, 31-49.

[5] Correa, P. Helicobacter pylori and gastric carcinogenesis. Am J Surg Pathol (1995). SS43., 37.

[6] Correa, P. Human gastric carcinogenesis: a multistep and multifactorial process-First American Cancer Society Award Lecture on Cancer Epidemiology and Prevention. Cancer Research (1992). , 52, 6735-6740.

[7] Hamilton, J. P, \& Meltzer, S. J. A review of the genomics of gastric cancer. Clin Gastroenterol Hepatol (2006). , 4(4), 416-425.

[8] Yamashita, K, Sakuramoto, S, \& Watanabe, M. Genomic and epigenetic profiles of gastric cancer: potential diagnostic and therapeutic applications. Surg Today (2011). , 41(1), 24-38.

[9] Panani, A. D. Cytogenetic and molecular aspects of gastric cancer: clinical implications. Cancer Lett, (2008). , 266(2), 99-115.

[10] Costa, N. R, Sousa, A, Teixeira, C, Castro, J, Guimaraes, N, \& Santos-silva, F. Oncogenic Signaling in Gastric Cancer. Rijeka: In Tech; (2011).

[11] Hudler, P, Vogelsang, M, \& Komel, R. Genetic Instability in Gastric Cancer. Rijeka: In Tech; (2011).

[12] Goldstone, A. R, Quirke, P, \& Dixon, M. F. Helicobacter pylori infection and gastric cancer.Journal of Pathology(1996). , 179, 129-137.

[13] Nabewera, H. M, \& Logan, R. P. Epidemiology of Helicobacter pylori infection: transmission, translocation and extragastric reservoirs. J Physiol Pharmacol (1999). , 50, 711-722. 
[14] Forman, D, Newell, D. G, \& Fullerton, F. Association between infection with Helicobacter pylori and risk of gastric cancer: evidence from prospective investigation. BM] (1991). , 302, 1302-1305.

[15] Parsonnet, J, Friedman, G. D, Oremtreich, N, \& Vogelman, H. Risk for gastric cancer in people with CagA positive or CagA negative Helicobacter pylori infection. Gut (1997). , 40, 297-301.

[16] Watanabe, T, Tada, M, \& Nagai, H. Helicobacter pylori infection induces gastric cancer in Mongolian gerbils. Gastroenterology (1998). , 115, 642-648.

[17] Uemura, N, Okamoto, S, Yamamoto, S, Matsumura, N, Yamaguchi, S, Yamakido, M, Taniyama, K, Sasaki, N, \& Schlemper, R. J. Helicobacter pylori infection and the development of gastric cancer. New England Journal of Medicine (2001). , 345, 784-789.

[18] Fukase, K, Kato, M, Kikuchi, S, Inoue, K, Uemura, N, Okamoto, S, Terao, S, Amagai, K, Hayashi, S, \& Asaka, M. Effect of eradication of Helicobacter pylori on incidence of metachronous gastric carcinoma after endoscopic resection of early gastric cancer: an open-label, randomised controlled trial. Lancet (2008). , 372(9636), 392-397.

[19] Blaser, M. J, \& Berg, D. E. Helicobacter pylori genetic diversity and risk of human disease. Journal of Clinical Investigation (2001). , 107, 767-773.

[20] Isomoto, H, Mizuta, Y, Miyazaki, M, Takeshima, F, Omagari, K, Murase, K, Nishiyama, T, Inoue, K, Murata, I, \& Kohno, S. Implication of NF-kappaB in Helicobacter pylori-associated gastritis. American Journal of Gastroenterology (2000). , 95, 2768-2776.

[21] Sasaki, N, Morisaki, T, Hashizume, K, Yao, T, Tsuneyoshi, M, Noshiro, H, Nakamura, K, Yamanaka, T, Uchiyama, A, Tanaka, M, \& Katano, M. Nuclear factor-kappaB p65 (RelA) transcription factor is constitutively activated in human gastric carcinoma tissue. Clinical Cancer Research (2001).

[22] Tsang, Y. H, Lamb, A, Romero-gallo, J, Huang, B, \& Ito, K. Peek jr RM, Ito Y and Che LF. Helicobacter pylori CagA targets gastric tumor suppressor RUNX3 for proteasomemediated degradation. Oncogene (2010). , 29(41), 5643-5650.

[23] Martin, T. E, Powell, C. T, Wang, Z, Bhattacharyya, S, Walsh-reitz, M. M, Agarwal, K, \& Toback, F. G. A novel mitogenic protein that is highly expressed in cells of the gastric antrum mucosa. AJP Gastrointesinal and Liver Physiology (2003). GG343., 332.

[24] Yoshikawa, Y, Mukai, H, Hino, F, Asada, K, \& Kato, I. Isolation of two novel genes, downregulated in gastric cancer. Japanese Journal of Cancer Research (2000). , 91, 459-463.

[25] Oien, K. A, Mcgregor, F, Butler, S, Ferrier, R. K, Downie, I, Bryce, S, Burns, S, \& Keith, W. N. Gastrokine 1 is abundantly and specifically expressed in superficial gastric epithelium, down-regulated in gastric carcinoma, and shows high evolutionary conservation. Journal of Pathology (2004). , 203, 789-797. 
[26] Rippa, E, Martin, G, \& Rocco, A. La Monica G, Fiengo A, Siciliano RA, Cacace G, Malori A, Nardone G, Arcari P. Changes of protein expression in Helicobacter pylori-infected human gastric mucosa. Current Topics in Peptide \& Protein Research (2007). , $8,35-43$.

[27] Nardone, G, Rippa, E, Martin, G, Rocco, A, Siciliano, R. A, Fiengo, A, Cacace, G, Malorni, A, Budillon, G, \& Arcari, P. Gastrokine 1 expression in patients with and without Helicobacter pylori infection. Digestive and Liver Disease (2007). , 39, 122-129.

[28] Nardone, G, Martin, G, Rocco, A, \& Rippa, E. La Monica G, Caruso F, Arcari P. Molecular expression of gastrokine 1 in normal mucosa and in Helicobacter pylori related preneoplastic and neoplastic gastric lesions. Cancer Biology and Therapy (2008). , 7, 1890-1895.

[29] Shiozaki, K, Nakamori, S, Tsujie, M, Okami, J, Yamamoto, H, Nagano, H, Dono, K, Umeshita, K, Sakon, M, Furukawa, H, Hiratsuka, M, Kasugai, T, Ishiguro, S, \& Monden, M. Human stomachspecific gene, CA11, is down-regulated in gastric cancer. Internal Journal of Oncology (2001). , 19, 701-707.

[30] Du, J. J, Dou, K. F, Peng, S. Y, Wang, W. Z, Wang, Z. H, Xiao, H. S, Guan, W. X, Liu, Y. B, \& Gao, Z. Q. Down-regulated full-length novel gene GDDR and its effect on gastric cancer. Zhonghua Yi Xue Za Zhi (2003). , 10, 1166-1168.

[31] Yoon, J. H, Kang, Y. H, Choi, Y. J, Park, I. S, Nam, S. W, Lee, J. Y, Lee, Y. S, \& Park, W. S. Gastrokine 1 functions as a tumor suppressor by inhibition of epithelial-mesenchymal transition in gastric cancers. Journal of Cancer Research and Clinical Oncology (2011). , 137, 1697-1704.

[32] Xing, R, Li, W, Cui, J, Zhang, J, Kang, B, Wang, Y, Wang, Z, Liu, S, \& Lu, Y. Gastrokine 1 induces senescence through $\mathrm{Rb}$ pathway activation in gastric cancer cells. Gut (2011). , 16.

[33] Rippa, E. La Monica G, Allocca R, Romano MF, De Palma M, Arcari P. Overexpression of gastrokine 1 in gastric cancer cells induces fas-mediated apoptosis. Journal of Cellular Physiology (2011). , 226, 2571-2578.

[34] Moss, S. F, Lee, J. W, Sabo, E, Rubin, A. K, Rommel, J, Westley, B. R, May, F. E, Gao, J, Meitner, P. A, Tavares, R, \& Resnick, M. B. Decreased expression of gastrokine 1 and the trefoil factor interacting protein TFIZ1/GKN2 in gastric cancer: influence of tumor histology and relationship to prognosis. Clinical Cancer Research (2008). , 14(13), 4161-4167.

[35] Yoon, J. H, Song, J. H, Zhang, C, Jin, M, Kang, Y. H, Nam, S. W, Lee, J. Y, \& Park, W. $\mathrm{S}$. Inactivation of the Gastrokine 1 gene in gastric adenomas and carcinomas. Journal of Pathology (2011). , 223, 618-625.

[36] Katoh, M, \& Katoh, M. WNT signaling pathway and stem cell signaling network. Clinical Cancer Researh (2007). , 13, 4042-4045. 
[37] Kemler, R. From cadherins to catenins: cytoplasmic protein interactions and regulation of cell adhesion. Trends in Genetics (1993). , 9, 317-321.

[38] Desbois-mouthon, C, \& Cadoret, A. Blivet-Van Eggelpoel MJ, et al. Insulin and IGF-1 stimulate the beta-catenin pathway through two signalling cascades involving GSK-3beta inhibition and Ras activation. Oncogene (2001). , 20(2), 252-259.

[39] Moon, R. T, Bowerman, B, Boutros, M, \& Perrimon, N. The promise and perils of Wnt signaling through beta-catenin. Science (2002). , 296(5573), 1644-1646.

[40] Lu, Z, Ghosh, S, Wang, Z, \& Hunter, T. Downregulation of caveolin-1 function by EGF leads to the loss of E-cadherin, increased transcriptional activity of beta-catenin, and enhanced tumor cell invasion. Cancer Cell. (2003). , 4(6), 499-515.

[41] Huang, H. He X.Wnt/beta-catenin signaling: new (and old) players and new insights. Current Opinion in Cell Biology (2008). , 20, 119-125.

[42] Nakayama, M, Hisatsune, J, Yamasaki, E, Isomoto, H, \& Kurazono, H. Hatakeyama Azuma T, Yamaoka Y, Yahiro K, Moss J, Hirayama T. Helicobacter pylori VacA-induced inhibition of GSK3 through the PI3K/Akt signaling pathway. Journal of Biological Chemistry (2009). , 284, 1612-1619.

[43] Becker, K. F, Atkinson, M. J, Reich, U, Becker, I, Nekarda, H, \& Siewert, J. R. Hofle r $\mathrm{H}$. E-cadherin gene mutations provide clues to diffuse type gastric carcinomas. Cancer Research (1994). , 54, 3845-3852.

[44] Wijnhoven, B. P, \& Dinjens, W. N. Pignatelli M. E-cadherin-catenin cell-cell adhesion complex and human cancer. British Journal of Surgery (2000). , 87, 992-1005.

[45] Smith, M. E, \& Pignatelli, M. The molecular histology of neoplasia: the role of the cadherin/catenin complex. Histopathology (1997). , 31, 107-111.

[46] Tucker, E. L, \& Pignatelli, M. Catenins and their associated proteins in colorectal cancer. Histology and Histopathology (2000). , 15, 251-260.

[47] Kawanishi, J, Kato, J, Sasaki, K, Fujii, S, Watanabe, N, \& Niitsu, Y. Dysfunction of Ecadherin due to mutation of beta-catenin in a scirrhous gastric cancer cell line. Nihon Rinsho. (1995). , 53(7), 1590-1594.

[48] Shibata, T, Ochiai, A, Kanai, Y, Akimoto, S, Gotoh, M, Yasui, N, Machinami, R, \& Hirohashi, S. Dominant negative inhibition of the association between beta-catenin and c-erbB-2 by N-terminally deleted beta-catenin suppresses the invasion and metastasis of cancer cells. Oncogene (1996). , 13(5), 883-889.

[49] Caca, K, Kolligs, F. T, Ji, X, Hayes, M, Qian, J, Yahanda, A, Rimm, D. L, Costa, J, \& Fearon, E. R. Beta- and gamma-catenin mutations, but not E-cadherin inactivation, underlie T-cell factor/lymphoid enhancer factor transcriptional deregulation in gastric and pancreatic cancer. Cell Growth Differentation Journal (1999). , 10(6), 369-376.

[50] Oliveira, C, Senz, J, Kaurah, P, Pinheiro, H, Sanges, R, Haegert, A, Corso, G, Schouten, J, Fitzgerald, R, Vogelsang, H, Keller, G, Dwerryhouse, S, Grimmer, D, Chin, S. F, 
Yang, H. K, Jackson, C. E, Seruca, R, Roviello, F, Stupka, E, Caldas, C, \& Huntsman, D. Germline CDH1 deletions in hereditary diffuse gastric cancer families. Human Molecular Genetics (2009). , 18, 1545-1555.

[51] Cheng, X. X, Wang, Z. C, Chen, X. Y, Sun, Y, Kong, Q. Y, Liu, J, Gao, X, Guan, H. W, \& Li, H. Frequent loss of membranous E-cadherin in gastric cancers: A cross-talk with Wnt in determining the fate of beta-catenin. Clinical and Experimental Metastasis (2005). , 22, 85-93.

[52] Humar, B, Blair, V, Charlton, A, More, H, \& Martin, I. Guilford P. E-cadherin deficiency initiates gastric signet-ring cell carcinoma in mice and man. Cancer Research (2009). , 69, 2050-2056.

[53] Ebert, M. P, Fei, G, Kahmann, S, Müller, O, Yu, J, Sung, J. J, \& Malfertheiner, P. Increased beta-catenin mRNA levels and mutational alterations of the APC and betacatenin gene are present in intestinal-type gastric cancer. Carcinogenesis (2002). , 23, 87-91.

[54] Fang, D. C, Luo, Y. H, Yang, S. M, Li, X. A, Ling, X. L, \& Fang, L. Mutation analysis of APC gene in gastric cancer with microsatellite instability. World Journal of Gastroenterolology (2002). , 8, 787-791.

[55] Offerhaus, G. J, Giardiello, F. M, Krush, A. J, Booker, S. V, Tersmette, A. C, Kelley, N. C, \& Hamilton, S. R. The risk of upper gastrointestinal cancer in familial adenomatous polyposis. Gastroenterology (1992). , 102, 1980-1982.

[56] Otto, F, Lübbert, M, \& Stock, M. Upstream and downstream targets of RUNX proteins. Journal of Cellular Biochemistry (2003). , 89, 9-18.

[57] Ito, Y. Oncogenic potential of the RUNX gene family: 'overview'. Oncogene (2004). , 23, 4198-4208.

[58] Li, Q. L, Ito, K, Sakakura, C, Fukamachi, H, Inoue, K, Chi, X. Z, Lee, K. Y, Nomura, S, Lee, C. W, Han, S. B, Kim, H. M, Kim, W. J, Yamamoto, H, Yamashita, N, Yano, T, Ikeda, T, Itohara, S, Inazawa, J, Abe, T, Hagiwara, A, Yamagishi, H, Ooe, A, Kaneda, A, Sugimura, T, Ushijima, T, Bae, S. C, \& Ito, Y. Causal relationship between the loss of RUNX3 expression and gastric cancer. Cell (2002). , 109, 113-124.

[59] Kim, T. Y, Lee, H. J, Hwang, K. S, Lee, M, Kim, J. W, Bang, Y. J, \& Kang, G. H. Methylation of RUNX3 in various types of human cancers and premalignant stages of gastric carcinoma. Laboratory Investigation (2004). , 84, 479-484.

[60] Sakakura, C, Hasegawa, K, Miyagawa, K, Nakashima, S, Yoshikawa, T, Kin, S, Nakase, Y, Yazumi, S, Yamagishi, H, Okanoue, T, Chiba, T, \& Hagiwara, A. Possible involvement of RUNX3 silencing in the peritoneal metastases of gastric cancers. Clinical Cancer Research. (2005). , 11(18), 6479-6488.

[61] Katayama, Y, Takahashi, M, \& Kuwayama, H. Helicobacter pylori causes runx3 gene methylation and loss of expression in gastric epithelial cells, which is mediated by ni- 
tric oxide produced by macrophages. Biochemical and Biophysical Research Communications (2009). , 388, 496-500.

[62] Hsu, P. I, Hsieh, H. L, Lee, J, Lin, L. F, Chen, H. C, Lu, P. J, \& Hsiao, M. Loss of RUNX3 expression correlates with differentiation, nodal metastasis, and poor prognosis in gastric cancer. Annals of Surgical Oncology (2009). , 16, 1686-1694.

[63] Lengauer, C, Kinzler, K. W, \& Vogelstein, B. Genetic instability in colorectal cancers. Nature (1997). , 386, 623-627.

[64] Thibodeau, S. N, Bren, G, \& Schaid, D. Microsatellite instability in cancer of the proximal colon. Science (1993). , 260, 816-819.

[65] Ionov, Y, Peinado, M. A, Malkhosyan, S, Shibata, D, \& Perucho, M. Ubiquitous somatic mutations in simple repeated sequences reveal a new mechanism for colonic carcinogenesis. Nature (1993). , 363, 558-561.

[66] Casali, P. G, Jost, L, Reichardt, P, Schlemmer, M, \& Blay, J. Y. ESMO Guidelines Working Group. Gastrointestinal stromal tumours: ESMO clinical recommendations for diagnosis, treatment and follow-up. Annals of Oncology (2009). suppl 4): 64-67.

[67] Warren, R. S, Yuan, H, Matli, M. R, Gillett, N. A, \& Ferrara, N. Regulation by vascular endothelial growth factor of human colon cancer tumorigenesis in a mouse model of experimental liver metastasis. Journal of Clinical Investigation (1995). , 95, 1789-1797.

[68] Slamon, D. J, Clark, G. M, Wong, S. G, Levin, W. J, Ullrich, A, \& Mcguire, W. L. Human breast cancer: correlation of relapse and survival with amplification of the HER-2/neu oncogene. Science (1987). , 235, 177-182.

[69] Nicholson, R. I, Gee, J. M, \& Harper, M. E. EGFR and cancer prognosis. European Journal of Cancer (2001). S, 9-15.

[70] Slamon, D. J, Leyland-jones, B, Shak, S, Fuchs, H, Paton, V, Bajamonde, A, Fleming, T, Eiermann, W, Wolter, J, Pegram, M, Baselga, J, \& Norton, L. Use of chemotherapy plus a monoclonal antibody against HER2 for metastatic breast cancer that overexpresses HER2. New England Journal of Medicine (2001). , 344, 783-792.

[71] Jørgensen, J. T. Targeted HER2 treatment in advanced gastric cancer. Oncology (2010). , 78, 26-33.

[72] Pinto, C. Di Fabio F, Siena S, Cascinu S, Rojas Llimpe FL, Ceccarelli C, Mutri V, Giannetta L, Giaquinta S, Funaioli C, Berardi R, Longobardi C, Piana E, Martoni AA. Phase II study of cetuximab in combination with FOLFIRI in patients with untreated advanced gastric or gastroesophageal junction adenocarcinoma (FOLCETUX study). Annals of Oncology (2007). , 18, 510-517.

[73] Liu, X, Guo, W. J, Zhang, X. W, Cai, X, Tian, S, \& Li, J. Cetuximab enhances the activities of irinotecan on gastric cancer cell lines through downregulating the EGFR path- 
way upregulated by irinotecan. Cancer Chemotherapy and Pharmacology (2011). , 68(4), 871-878.

[74] Corso, G, Velho, S, Paredes, J, Pedrazzani, C, Martins, D, Milanezi, F, Pascale, V, Vindigni, C, Pinheiro, H, Leite, M, Marrelli, D, Sousa, S, Carneiro, F, Oliveira, C, Roviello, F, \& Seruca, R. Oncogenic mutations in gastric cancer with microsatellite instability. European Journal of Cancer (2011). , 47(3), 443-451.

[75] El-Rayes, B. F, Patel, B, Zalupski, M, Hammad, N, Shields, A, Heilbrun, L, Venkatramanamoorthy, R, \& Philip, P. A phase II study of bevacizumab, oxaliplatin, and docetaxel in locally advanced and metastatic gastric and gastroesophageal junction cancers. Annals of Oncology (2010). , 21(10), 1999-2004.

[76] Tuccillo, C, Cuomo, A, Rocco, A, Martinelli, E, Staibano, S, Mascolo, M, Gravina, A. G, Nardone, G, Ricci, V, \& Ciardiello, F. Del Vecchio Blanco C, Romano M. Vascular endothelial growth factor and neo-angiogenesis in H. pylori gastritis in humans. Journal of Pathology (2005). , 207(3), 277-284.

[77] Stegmeier, F, Warmuth, M, Sellers, W. R, \& Dorsch, M. Targeted cancertherapies in the twenty-first century: lessons from imatinib. Clinical Pharmacology \& Therapeutics (2010). , 87, 543-552.

[78] Claffey, K. P, \& Brown, L. F. del Aguila LF, Tognazzi K, Yeo KT, Manseau EJ, Dvorak HF. Expression of vascular permeability factor/vascular endothelial growth factor by melanoma cells increases tumor growth, angiogenesis, and experimental metastasis. Cancer Research (1996). , 56, 172-181.

[79] Karayiannakis, A. J, Syrigos, K. N, Polychronidis, A, Zbar, A, Kouraklis, G, Simopoulos, C, \& Karatzas, G. Circulating VEGF levels in the serum of gastric cancer patients: correlation with pathological variables, patient survival, and tumor surgery. Annals of Surgery (2002). , 236, 37-42.

[80] Bjornsti, M. A, \& Houghton, P. J. The TOR pathway: a target for cancer therapy. Nat Rev Cancer (2004). , 4(5), 335-348.

[81] Edinger, A. L, \& Thompson, C. B. Akt maintains cell size and survival by increasing mTORdependent nutrient uptake. Molecular Biology of the Cell (2002). , 13, 2276-2288.

[82] Fingar, D. C, Richardson, C. J, Tee, A. R, Cheatham, L, Tsou, C, \& Blenis, J. mTOR controls cell cycle progression through its cell growth effectors S6K1 and 4E-BP1/ eukaryotic translation initiation factor 4E. Molecular and Cellular Biology (2004). , 24, 200-216.

[83] Patel, P. H, Chadalavada, R. S, Chaganti, R. S, \& Motzer, R. J. Targeting von HippelLindau pathway in renal cell carcinoma. Clinical Cancer Research (2006). , 12, 7215-7220. 
[84] Hay, N, \& Sonenberg, N. Upstream and downstream of mTOR. Genes Development. (2004). , 18, 1926-1945.

[85] Wullschleger, S, Loewith, R, \& Hall, M. N. TOR signaling in growth and metabolism. Cell (2006). , 124, 471-484.

[86] Faivre, S, Kroemer, G, \& Raymando, E. Current development of mTOR inhibitors as anticancer agents. Nature Reviews Drug Discovery (2006). , 5, 671-688.

[87] Wagner, A. J, Malinowska-kolodziej, I, Morgan, J. A, Qin, W, Fletcher, C. D, Vena, N, Ligon, A. H, Antonescu, C. R, Ramaiya, N. H, Demetri, G. D, Kwiatkowski, D. J, \& Maki, R. G. Clinical activity of mTOR inhibition with sirolimus in malignant perivascular epithelioid cell tumors: targeting the pathogenic activation of mTORC1 in tumors. Journal of Clinical Oncology (2010). , 28, 835-840.

[88] Yu, G, Wang, J, Chen, Y, Wang, X, Pan, J, Li, G, Jia, Z, Li, Q, Yao, J. C, \& Xie, K. Overexpression of phosphorylated mammalian target of rapamycin predicts lymph node metastasis and prognosis of chinese patients with gastric cancer. Clinical Cancer Research (2009). , 15, 1821-1829.

[89] Donnell, O, Faivre, A, Burris, S, Rd, H. A, Rea, D, Papadimitrakopoulou, V, Shand, N, Lane, H. A, Hazell, K, Zoellner, U, Kovarik, J. M, Brock, C, Jones, S, Raymond, E, \& Judson, I. Phase I pharmacokinetic and pharmacodynamic study of the oral mammalian target of rapamycin inhibitor everolimus in patients with advanced solid tumors. Journal of Clinical Oncology (2008). , 26, 1588-1595.

[90] Matsuzaki, T, Yashiro, M, Kaizaki, R, Yasuda, K, Doi, Y, Sawada, T, Ohira, M, \& Hirakawa, K. Synergistic antiproliferative effect of mTOR inhibitors in combination with 5-fluorouracil in scirrhous gastric cancer. Cancer Sci (2009). , 100, 2402-2410. 